\title{
Get Involved: Alexis Lewis, Conference Organizer
}

Kelly Zappas

"Get Involved" is a recurring End Notes feature that spotlights the work of TMS volunteers and shows the wide range of activities available through TMS. This month, Alexis Lewis, materials research engineer at the Naval Research Laboratory in Washington, D.C., discusses her volunteer experiences with TMS and as lead organizer for the upcoming 3D Materials Science 2012 Conference, a new TMS specialty conference planned for July.

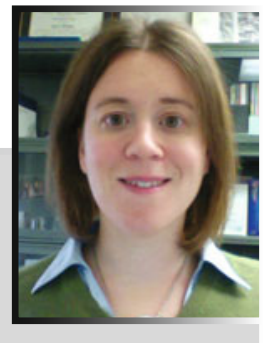

Q. How did you get started as a volunteer with TMS?

A. I started as a member of the Mechanical Behavior of Materials Committee, when I was a postdoc at the Naval Research Laboratory (NRL), in 2003. I had been a student member of TMS prior to graduation, since undergrad.

Q. Did you find it difficult to get involved? What would you recommend to other potential volunteers?

A. I found it quite easy to become involved with TMS's activities-I was fortunate that my colleagues at NRL are very active in TMS committees, and they encouraged me to join. I would recommend to anyone interested to simply show up to a committee meeting at a TMS Annual Meeting or MS\&T. The committee meeting times are usually posted well enough in advance of the conference, and all of the committees I have worked with were eager to welcome new members.

Q. How did the 3D Materials Science 2012 Conference come about and how did you become involved with it?

A. This meeting came out of several very successful symposia at TMS and MS\&T Meetings on 3D Materials Science. I have worked in the field of 3D Materials Science since 2003, and have been an active participant and organizer in the 3D Materials Science symposia. George Spanos, the conference's TMS liaison, approached me last year with the idea to broaden the scope from a symposium to a specialty conference. I agreed that the timing was perfect - and as is evidenced by the nearly 200 abstract submissions we received, we were correct. The interest and activity in this field is increasing exponentially every year.

Q. Why do you think a conference was needed on this topic?

A. Early on in the timeline of 3D Materials Science, only a few groups had the capabilities and facilities to collect and analyze 3D microstructures. By the time of the sixth 3D Materials Science symposium, in 2010, it was apparent that the community had moved beyond qualitative analysis and into making real microstructural measurements and understanding structure-property relationships in 3D. Now, many groups around the world are beginning to adopt 3D characterization and analysis techniques, and a handful of groups have developed very advanced experimental and computational tools. A specialty conference in a focused setting is the perfect place for these researchers and students to exchange ideas and results.

Q. What kind of work is involved in organizing a specialty conference?

A. I had been involved with the 3D Materials Science symposia in the past, but the work required for symposium organization is just a fraction of what needs to be considered when planning an entire conference. I've had input in everything from site selection, budgeting, and deciding on the confer- ence format, to coordinating sponsorship - and we're still several months away from the conference. While it is a lot of work, we have received many excellent abstracts and it looks like it is going to be a great conference. I'm really looking forward to it.

Q. You are currently chair of the Advanced Characterization, Testing, and Simulation (ACTS) Committee and a member of the Mechanical Behavior of Materials and Women in Science committees. How do you balance these activities?

A. For all of the committees I've joined through TMS, members can be as active as they like. In the past two years, I've stepped down my activity in other committees while chairing ACTS. My term as chairman ends at the upcoming TMS Annual Meeting, though, so I anticipate becoming more active with the other committees at that time.

Q. How do you think your experiences as a TMS volunteer help you professionally?

A. Being part of a TMS committee has given me the opportunity to contribute to conference programming, which is a great way to play an active role in shaping the direction of your field. I've learned a lot from organizing the 3DMS conference. I've been lucky to have four great co-organizers, who have all been working very hard to keep things moving along and to ensure the conference will be successful.

Kelly Zappas is a contributing writer for JOM. 